\title{
Implicit Evaluation of Ideational Meaning in News Discourse
}

\author{
Zhipeng Liu \\ School of foreign languages \\ Taishan University \\ Taian, Shandong, China
}

\begin{abstract}
The study of news discourse evaluation focuses on the explicit attitude caused by attitude-invoking vocabulary. What lacks now is a discussion of implicit attitude that seems neutral but implies author's judgment. Attitude, engagement and graduation are the three subsystems of evaluation theory. They are inseparable from each other. This paper starts from the perspective of engagement and graduation, comprehensively identifies and analyzes the implicit attitude of ideational meaning in news discourse, and explores its function of coordinating positioning and alliance with the readers.
\end{abstract}

Keywords—News discourse; Conceptual meaning; Implicit evaluation

\section{INTRODUCTION}

Discourse reflects the meaning of evaluation, and the expression of evaluation meaning reflects the attitude, emotion and ideology of the discourse organizer. The news discourse is no exception. It also expresses the interpretation of an event by the news media and conveys a variety of indirect or direct, supportive or opposing attitudes. In the current linguistic world, it is a hot topic to analyze and explore the deep-seated attitudes and values implied in news discourse from the perspective of evaluation theory. Martin and White (2005) pointed out three approaches to realize implicit attitude: the provocation of discourse metaphor, the flagging of graduation resources and the affording of ideational meaning [5]. The implicit attitude in the ideational meaning is mainly embodied by the transitivity system. The transitivity system belongs to the theoretical framework of systemic functional linguistics, consisting of processes, event participants, and event environmental components. Discourse constructors use different transitivity systems to highlight and imply a specific evaluation attitude.

The news text always expresses the news reporters' attitude, as well as the media's stance and ideology. Fowler (1991) pointed out that the media tend to employ language resources, which are encoded with certain covert attitudinal denotation, to report the events happening besides us in order to coordinate the stance and align the readers [1]. Martin's Appraisal System Theory (AST) provides a powerful analytic tool for evaluation analysis of news text. It consists of three sub-systems: attitude, engagement and graduation. According to Martin, the evaluation in the text is divided into the explicit and implicit evaluation. The explicit evaluation is regularly realized through the vocabulary with clear attitudinal meaning, while the implicit is expressed by some neutral semantic structure (but with attitudinal denotation) in the text. There are three approaches to realize the implicit evaluation (Martin \& White, 2005): the lexical metaphor provokes the evaluation; the ideational meaning affords the evaluation; and the resources of graduation flag the evaluation [5]. Graduation is the sub-system of Martin's AST, and it is central to the entire Appraisal system. Both attitude and engagement are always realized and mediated through the graduation. This paper aims to analyze the play of graduation in invoking the attitude and then explore the ideology and the stance in the news text.

\section{RESEARCH ON ENGLISH NEWS TEXT FROM THE PERSPECTIVE OF EVALUATION THEORY}

The evaluation theory "focuses on and explores the attitudes and emotions in the discourse to achieve the purpose of the alliance with communication partner (Martin and Ross 2003: 23)[4]." The evaluative attitude may be explicit or implicit. The explicit attitude is expressed by the words that clearly highlight the author's attitude and feeling, and the implicit attitude is triggered by the neutral words or semantic structure that highlights the author's certain emotions and wishes. In recent years, the evaluation researches on domestic news discourse have been continuous and fruitful. From the research methods of evaluation, it can be divided into: critical reading strategy research [2](Liu Chengyu 2002), social cognitive model and intertextual analysis [7](Zhang Lei 2007) and critical discourse analysis [6](Shan Shengjiang 2011).In summary, although scholars have obtained satisfactory results in the field of implicit evaluation of news discourse, these studies focus on explicit evaluation resources, and the research on the implicit attitudes induced by ideational meaning is still weak. Attitude, engagement, and graduation are important components of Martin's evaluation theory. They are the disintegrated whole. Therefore, this paper intends to analyze the implicit attitude resources in news discourse from the perspective of engagement and graduation, and explore the function of implicit attitude resource in positioning readers to achieve consistency between subjects. Taking the event of the 2014 Ukrainian crisis as an example, this article uses the 23 news reports related to this event in the China Daily (March $17-23,2014)$ as a corpus to further explore and analyze the hidden implicit attitude in the discourse. 


\section{IMPLICIT ATTITUDE AND ENGAGEMENT IN IDEATIONAL MEANING}

Zhu Yongsheng [8] (2009) argues that the implicit evaluation of ideational meaning refers to the implicit expression of the attitude of the speaker through the use of the lexical semantic structure of the objective and descriptive nature of the transitivity system. In the actual discourse, the author implies a certain attitude by producing a sentence in which we make selection of the different transitive process, the arrangement of the event participants and the environmental components in the sentence. Engagement, graduation and attitude are the three subsystems of the evaluation theory. The engagement system points to the origin of the attitude in semantic resources, and can be subdivided into monogloss and heterogloss. Engagement and attitude are interrelated and inseparable. As long as the author is engaged in presenting the objective event in the situation, it will show the attitude; the expressive way of engagement can indicate the intensity of the attitude.

\section{A. Implicit evaluation and monogloss system}

The monogloss engagement system, as the name suggests, means that there is only one voice in the discourse, which excludes the dialogue between the two parties; in the discourse, only the author's voice describes what happened, so monogloss engagement is also called subjective engagement. Lyons (1977: 794)[3] interprets monogloss as an objective, simple assertion that is factual. However, in the description of seemingly objective ideational meaning, although there is no obvious attitude vocabulary, the author can convey the author's attitude through the selection of various components of the transitive structure, such as:

(1) Earlier this week, the EU and the United States imposed sanctions on certain individuals that were involved in the referendum in Crimea over joining the Russian Federation.

(2) Eastern and southern regions of Ukraine that are home to huge members of ethnic Russians will, supported by Russia, continue to demand more autonomy from Kiev.

The first clause in (1) is a clause of material process, and the process verb impose is explained as force somebody or something to have to deal with something that is difficult or unpleasant, with obvious coercive attitude meaning, carries the strong derogatory meaning. At the same time, the Actor of the clause is the world's superpowers of the European Union and the United States, and the Recipient is a certain individual. So, this clause indicates a sanction against the individual by the hegemonic countries, which obviously implies two Power Group's stance of bullying small countries and suggests the author's negative judgment on the behavior of the EU and the United States. The first clause in case (2) is a clause of the relational process, and the Attribute is "home". This sentence indicates that the southeastern part of Ukraine is the "homeland" of a large number of Russian ethnic groups, highlighting this viewpoint that people are eager to break away from Ukraine and determined to join Russia.

\section{B. Implicit evaluation and heterogloss system}

Heterogloss systems characterize dialogue, and there are interactions and collisions between the author's voice and different external sounds and opinions. The heterogloss systems can be subdivided into dialogic contraction and dialogic expansion. Dialogic contraction refers to the speaker's use of ingenious language strategy to combat or reject opposite arguments and voices, and the diversity of the negotiation dialogue space between the two sides is closed. On the contrary, the dialogic expansion accepts or recognizes other possible positions or arguments with a unique speech strategy, and the dialogue space of the diversity of the two sides of the communication is opened. Please see the example below:

(3)We now have grounds to state the measures being taken today are enough to prevent a repeat of the Crimean scenario in Ukraine's southeastern regions.

(4) The post-Cold War era seems to be over as we enter what could be renamed the inter-Cold War era.

Example (3) is a sub-category pronouncement of announcement in dialogic contraction. By explicitly intervening in the discourse, the speaker strongly expresses his or her own views and challenges other viewpoints, thus compressing the space for dialogue with different opinions. "We now have grounds to state..." strongly expresses the view that the measures we have taken are sufficient and correct to prevent the recurrence of Crimean autonomy in the south-eastern part of Ukraine. Cases (3) and (4) are accepted in the discourse expansion. Unlike the announcement, entertainment allows for the existence of different sounds and creates a multi-voice space. The author projects the opposing opinions to a subset of readers and forms an alliance with these readers. Entertainment is usually exemplified by modal and evidential language resources. The proposition of "the post-Cold War era seems to be over" in Example (4) indicates the existence of another proposition: the post-Cold War era did not end. In the case of (4), the relational process clause "It is also probable..." indicates the possibility of the subsequent proposition, and implicitly expresses the existence of the opposite proposition.

\section{IMPLICIT EVALUATION AND GRADUATION IN IDEATIONAL MEANING}

The graduation is a phenomenon that experts and scholars in the field of linguistics have been paying attention to. It focuses on the power scale of the attitude expressed by the language resources, and refers to the quantification and grading of the attitude meaning in the language resources. The graduation can be divided into two sub-systems: force and focus. The force in the evaluation system involves the intensity of quality and the number of things, and can be subdivided into two sub-categories of intensification and quantification. Focus and force are different, and focus concentrates on the degree of typicalization of the category of things. According to the strength of the linguistic semantic value, the focus is composed of two sub-categories of sharpening and softening poles. 


\section{A. Implicit evaluation and language}

The quantification and intensification of discourse resources in the language is a disjunction relationship within the theoretical framework of systemic functional linguistics. Intensification is the evaluation of quality and process, usually embodied by adverbs, which can modify adjectives, adverbs, and process verbs. Quantification is a semantic evaluation of the characteristics of the quantity, volume and extent of a physical entity. Extent is subdivided into temporal and spatial proximity and distribution in precision. The force and focus can be extended to two types of rising and falling poles, according to the strength of the semantic value. So how are the graduation realized in the news discourse? Please see the following example:

(5) UN Secretary-Ban Ki-moon is visiting Moscow on Thursday [quantitative: extent] and is to come to Ukraine [quantitative: extent] on Friday [quantitative: extent]. His visit will follow hot on the heels of tense scenes At the UN Security Council in New York [quantification: extent]. It was the council's eighth meeting [quantification: quantity] in less than three weeks [quantification: extent] on Ukraine.

(6) Crimean voted overwhelmingly [enhancement: process] on Sunday to secede from Ukraine and seek to join Russia. The hastily [enhancement: process] called vote was held two weeks [quantification: span] after Russian troops had moved into the Black Sea Peninsula.

The distribution of the quantity eighth and the extent in less than three weeks with the decreasing strength in (5), indicates that the United Nations has made slow progress in the Ukrainian resolution, highlights the deep rift between US and European interests, and carries a certain connotation of negative judgment. In this case, the time extent on Thursday and on Friday and the spatial extent to Ukraine and at the UN Security Council in New York highlight the UN Secretary-General's attempts to solve the Ukrainian crisis and the Russian-Uzbek territorial dispute. So the complexity of the crisis is obvious. The words of overwhelmingly and hastily in example (6) are intensified expression, highlighting the strong desire of the Crimean people to get rid of Ukrainian rule and join Russia. Similarly, in this sentence, two weeks is a quantifier of time extent, implying the author's positive evaluation of South Ukrainian entry into Russia.

\section{B. Implicit evaluation and focus}

Graduation according to prototypicality (focus) applies most typically to categories which, when viewed from an experiential perspective, are not scalable [4]. These are the clearly bounded, either-or categories which operate in experiential taxonomies where category membership is more or less precisely determined by some combination of sufficient and necessary conditions [4]. So, focus refers to grading things that are not empirically meaningful, dividing them according to the typical categories of things, and distinguishing between members of the center or peripheral category. Within the theoretical category of cognitive linguistics, the grading of the typicalization of things highlights the different understandings of human cognition to the surrounding world, attributing different meanings and attitudes to things. The focus of sharpening often indicates a positive attitude (such as a real man); on the contrary, the focus of softening implies a negative attitude (such as a bit). Specific examples are analyzed as follows:

(7) From the very start[focus: sharpening], the West has dismissed possibilities of armed intervention in the Crimean issue..... However, $\mathrm{Wu}$ from Tsinghua University warned of possible[focus: softening]conflicts between Russia and Ukraine.

(8) Moscow will not seek to restore the Soviet Union, but it will try to consolidate the Eastern Slav/Orthodox countries, as well as areas inhabited by some Muslim Turkic peoples, into a new Eurasian-compact[focus: softening]......

In Example (7), very means sharpening of the focus, and the rising semantic value clearly indicates that "from the beginning, the Western forces did not have the power to interfere with Crimean's intentions", highlighting the author's conviction of this proposition and implying positive evaluation. On the contrary, the use of the softening focus word "possible" indicates that the proposition - "the conflict between Russia and Ukraine" is uncertain, and the author's skepticism about this proposition is flagged. The Eurasian in (8) represents softening focus, and belongs to the semantic scope of the descending strength. This example shows that Russia is trying to develop the Orthodox state and turns the Muslim Turkic ethnic region into a new "Asia-Europe" treaty group. The softening focus word Eurasian shows that this new group has both Asian and European characteristics, highlighting its plausible features.

\section{CONCLUSION}

This paper explores the implicit evaluation of ideational meaning in English news discourse from the perspective of engagement and graduation. The generation of any discourse reflects the author's attitude, either explicit or implicit. Implicit attitudes are usually triggered by lexical grammatical structures that have no apparent attitude vocabulary. Attitude, engagement and graduation are the three subsystems of the evaluation theory. They are an interconnected whole.

The engagement system indicates the source of attitude. In the expression of ideational meaning, it intervenes in the communication system to construct the dialogue space between the subjects, and limits or accommodates different viewpoints. In this interpersonal interaction, the author and the reader form an alliance, and their intentions and attitudes are also transmitted and recognized. The graduation triggers the attitude through the flagging strategy, that is, guiding the reader's reading position through the ideational semantic feature, and indirectly expressing the attitude. 


\section{REFERENCES}

[1] Fowler, R. Language in the News: Discourse and Ideology in the Press [M]. London: Routledge, 1991.

[2] Liu Chengyu. Evaluation System in English News Discourse and Its Critical Reading [J]. Journal of school of Foreign Languages in Shandong Normal University, 2002, (4): 25-29.

[3] Lyons, J. 1977. Semantics. Cambridge: Cambridge University Press.

[4] Martin, J. R.\&D, Rose. Working with Discourse: Meaning beyond the Clause[M]. London: BookcraftLimited, 2003.

[5] Martin, J. R.\&P. R. R. White. The Language of Evaluation: Appraisal in English [M]. London / New York: Palgrave Macmillan, in press, 2005.

[6] Shan Shengjiang. Critical Discourse Analysis in News Discourse [J]. Journal of Foreign Languge, 2011, (6): 78-81.

[7] Zhang Lei. Evaluation Study in News Repor [J]. Journal of Tianjin Foreign Languages University, 2007, (5): 19-23.

[8] Zhu Yongsheng. Implicit Evaluation in Ideational Meaning [J]. Journal of Foreign Language Teaching, 2009, (4): 1-5. 